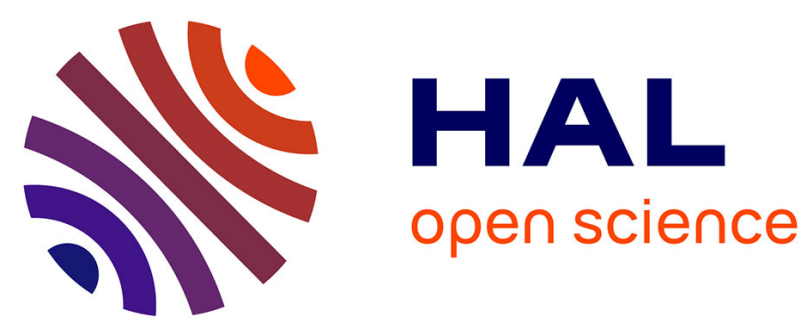

\title{
Towards a safe failure mode under short-circuit operation of power SiC MOSFET using optimal gate source voltage depolarization
}

Frédéric Richardeau, Frédéric Richardeau, Stephane Azzopardi

\section{- To cite this version:}

Frédéric Richardeau, Frédéric Richardeau, Stephane Azzopardi. Towards a safe failure mode under short-circuit operation of power SiC MOSFET using optimal gate source voltage depolarization. Microelectronics Reliability, 2021, pp.114258. 10.1016/j.microrel.2021.114258 . hal-03381418

\author{
HAL Id: hal-03381418 \\ https://hal.science/hal-03381418
}

Submitted on 16 Oct 2021

HAL is a multi-disciplinary open access archive for the deposit and dissemination of scientific research documents, whether they are published or not. The documents may come from teaching and research institutions in France or abroad, or from public or private research centers.
L'archive ouverte pluridisciplinaire HAL, est destinée au dépôt et à la diffusion de documents scientifiques de niveau recherche, publiés ou non, émanant des établissements d'enseignement et de recherche français ou étrangers, des laboratoires publics ou privés. 


\title{
Towards a safe failure mode under short-circuit operation of power $\mathrm{SiC}$ MOSFET using optimal gate source voltage depolarization
}

\author{
Wadia Jouha ${ }^{\mathrm{a}}$, Frédéric Richardeau ${ }^{\mathrm{a}}$, Stephane Azzopardi ${ }^{\mathrm{b}}$ \\ ${ }^{\text {a }}$ LAPLACE, University of Toulouse, CNRS, INPT, UPS, France \\ ${ }^{b}$ Safran Tech, SAFRAN TECH, Paris Saclay, France
}

\begin{abstract}
This paper focuses on the enhancement of the robustness level of SiC MOSFET during short-circuit conditions. In this study, two approaches allowing to ensure safe "Fail-To-Open" (FTO) mode in planar power SiC MOSFET devices under shortcircuit operation are presented. These approaches are based on direct depolarization of the gate source voltage and its estimation from the calculation of the critical dissipated power $\left(\mathrm{W} / \mathrm{mm}^{2}\right)$ between FTO and classical unsafe thermal runaway. They allow to determine the maximum value of the gate source voltage to preserve a FTO mode under a drain source voltage close to the nominal value i.e $V_{B R \min } / 2$. The boundary of the power density between FTO and "Fail-To-Short" (FTS) is introduced. A complete experimentation of the two failure modes in competition that may appear during short-circuit (SC) test of $1.2 \mathrm{kV} \mathrm{SiC} \mathrm{MOSFETs} \mathrm{is}$ presented. Finally, the penalty of the gate source voltage depolarization on the on-state resistance $\left(R_{d s(o n)}\right)$ is investigated in order to evaluate the techniques efficiency.
\end{abstract}

\section{Introduction}

Wide bandgap semiconductor materials like Silicon Carbide $(\mathrm{SiC})$ stands in the centre of attention for designing new power semiconductor devices thanks to their better intrinsic properties than Silicon ( $\mathrm{Si}$ ) [1]. SiC has interesting physical properties such as high electric field and high thermal conductivity that makes ability to ensure superior performances in high power applications (temperature, switching frequency, efficiency) [2]. SiC MOSFET are an effective technology solution to design high performance electrical-power switches that provides lower switching losses and high power density [3,4]. Beside the switching performance, $\mathrm{SiC}$ MOSFETs robustness in the industrial field is a major feature that must be considered for power conversion systems [5]. Indeed, SiC MOSFET capability in withstanding stressful conditions, such as short-circuit (SC) operation, is the main obstacle of the expansion of these devices to industrial applications.

Literature highlights several studies investigating the SC capability of SiC MOSFETs [6-9]. According to the literature, $\mathrm{SiC}$ MOSFETs may present, under short circuit operation, a competition between two failure modes. The first one is called drain-source Fail-To-Short (FTS) failure characterized by a drain-source short and leads to a permanent damage of the device. The second one is named drain-source Fail-To-Open (FTO) failure caused by a hard gate -source short-circuit path which $\mathrm{V}_{\mathrm{gs}}<\mathrm{V}_{\mathrm{gsth}}$ (threshold voltage) is applied.

The FTS mode is issued from a thermal runaway and/or the parasitic BJT latch-up inducing the local destruction of the die and the creation of a metallic path between drain and source. In the FTO mode, fusion and diffusion of the Al top metal through gate-cracks are observed [10]. This failure is related to the extreme heat in short-circuit between the poly silicon gate and the Al source. This metallic path can be located either on top of the chip between the gate fingers and the source pad below the passivation layer, and/or through the ILD (Inter-Layer Dielectric) across metallized cracks [11]. This is due to a very low coefficient of thermal expansion of the oxide compared to those of $\mathrm{Al}$ and $\mathrm{SiO}_{2}$. In the latter case, the short-circuit between the gate and source electrodes can lead to a permanent FTO mode if $\mathrm{V}_{\mathrm{gs}}<\mathrm{V}_{\text {gsth }}$ or a partial FTO mode if $\mathrm{V}_{\mathrm{gs}}>\mathrm{V}_{\text {gsth. }}$. In any case, FTO is clearly a more secure failure mode and is suitable for safety applications. In the literature [12], to preserve the FTO mode, a drain source voltage $\left(\mathrm{V}_{\mathrm{ds}}\right)$ depolarization method was used to reduce the power density crossing the chip in order to avoid thermal runaway. Obviously, this approach directly reduces the switching power capability to the same power semiconductor device.

This paper focuses on the faculty to obtain a FTO failure mode using the two above approaches based on direct depolarization of the gate source voltage $\left(\mathrm{V}_{\mathrm{gs}}\right)$ by reducing the buffer voltage $\left(\mathrm{V}_{\text {buffer }}\right)$. These approaches aim to determine the maximum value of $\mathrm{V}_{\mathrm{gs}}$ allowing a FTO mode to be maintained at a voltage $\mathrm{V}_{\mathrm{ds}}$ close to the nominal value i.e $\mathrm{V}_{\mathrm{BRmin}} / 2$ (eg.600 V for $1.2 \mathrm{kV}$ rating). The short circuit characterizations are performed on commercially available power SiC MOSFETs. The device performance and robustness are investigated under single pulse short circuit, for various $\mathrm{V}_{\text {buffer }}$ bias conditions and at room temperature $\mathrm{T}=25{ }^{\circ} \mathrm{C}$. This paper is organized as follow: first, the device under test and test protocol are presented. Then, the experimental results of $\mathrm{V}_{\mathrm{gs}}$ depolarization approach, the $\mathrm{V}_{\mathrm{gs}}$ estimation method and the penalty of these approaches on $\mathrm{R}_{\mathrm{ds}(\text { on })}$ are discussed.

\section{Device under test and test protocol}

\subsection{Device under test}


Table 1. Electrical characteristics of power device under test

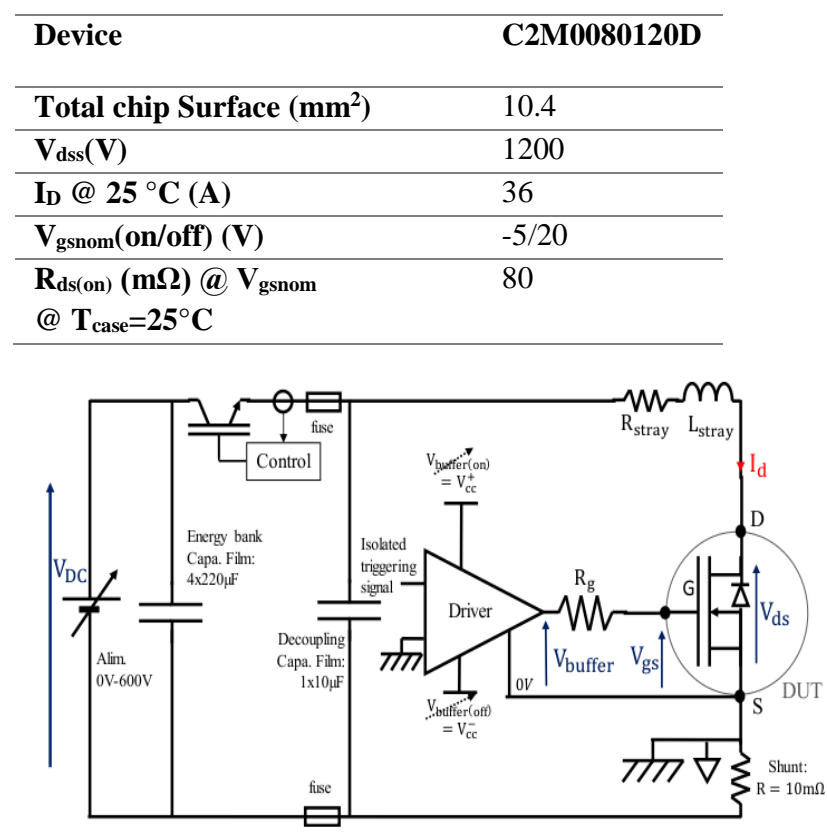

Fig. 1. Schematic of Type 1 short-circuit test [11].

In this work, short circuit tests are carried out on $1200 \mathrm{~V}$ planar SiC MOSFETs manufactured by Cree (C2M0080120D) [13]. Main electrical characteristics are presented in Table 1.

\subsection{Protocol of short circuit test}

Commercially power SiC MOSFET are examined under type 1 short circuit test. The test setup is presented in Fig.1. The characterization of the Device Under Test (DUT) under type 1 short-circuit test is performed by placing the DUT in the Low Side (LS) position and the High Side (HS) device is replaced by a strap bar. A circuit breaker based on Si IGBT mounted in series is used to protect the DUT from any damage after short-circuit failure. An adjustable gate drive was developed in order to drive the various DUT. The turn-on voltage $\left(\mathrm{V}_{\text {buffer(on) }}\right)$ can be adjusted from $9 \mathrm{~V}$ to $21.5 \mathrm{~V}$ and the turn-off voltage ( $\left.\mathrm{V}_{\text {buffer(off) }}\right)$ can be adjusted from $0 \mathrm{~V}$ to $-6 \mathrm{~V}$. The control signal for the driver is provided by an FPGA allowing to adjust the desired short-circuit duration through a touch screen. The FTO and / or FTS failure mode occurs by applying successive short circuit tests with increasing short circuit duration $\left(\mathrm{T}_{\mathrm{sc}}\right)$ by $1 \mu \mathrm{s}$ at each test. The DC bus voltage $\left(\mathrm{V}_{\mathrm{DC}}\right)$ or $\mathrm{V}_{\mathrm{ds}}$ is provided by a $\mathrm{DC}$ voltage supply $(0 \mathrm{~V}-600 \mathrm{~V}) . \mathrm{V}_{\mathrm{ds}}$ is gradually applied until the desired value is reached. A gate resistance $\left(R_{G}\right)$ fixed to $47 \Omega$ was used for this study for local measurement of gate leakage and permits a slow turn-off to avoid overvoltage without the use of a Soft Shut Down (SSD).

\section{Experimental results and discussion}

\subsection{Failure mode and Gate voltage depolarization}

Both FTS and FTO modes are controlled by the temperature

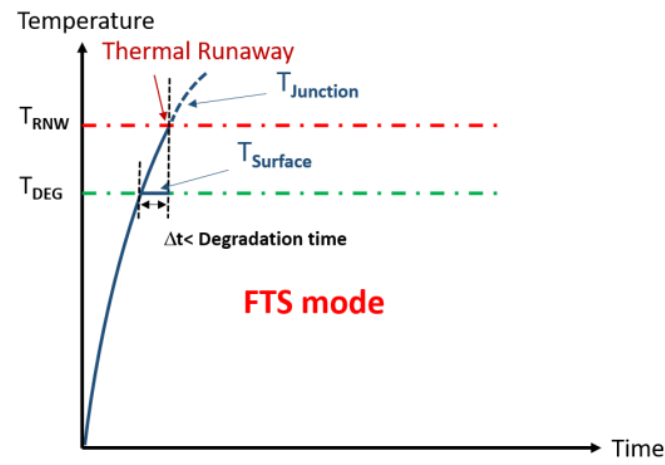

(a)

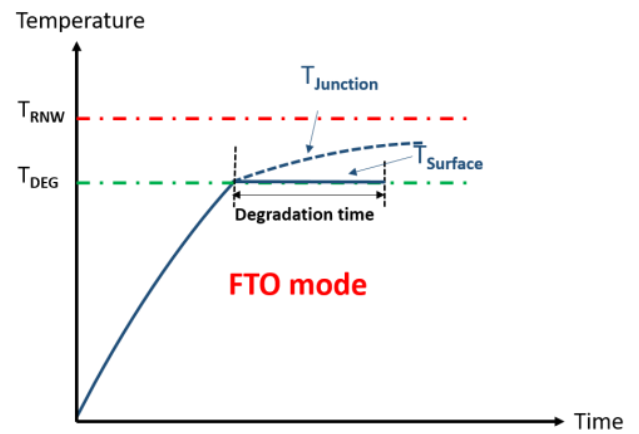

(b)

Fig. 2. Interpretation of two failures type [14]

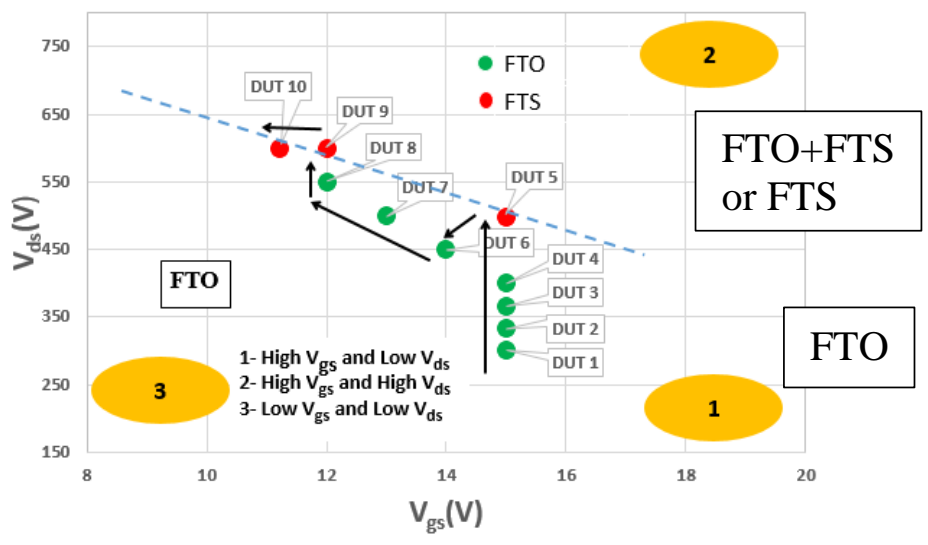

Fig. 3. Results of short circuit tests carried out on the C2M0080120D devices using a direct depolarization of $\mathrm{V}_{\text {gs. }}$ (FTO: fail-to-open, FTS : fail-to-short).

increase inside the device, and more precisely by its growth rate. In [14], the authors explain the appearance of these failure modes and its dependence on device temperature. This approach presented in Fig. 2.

From Fig. 2a, the FTS mode occurs when the junction temperature rises quickly and reaches a thermal runaway temperature $\left(\mathrm{T}_{\mathrm{RNW}}\right)$ in a time that does not allow the gate degradation delay time to be reached. If the device temperature remains between the degradation temperature $\left(\mathrm{T}_{\mathrm{DEG}}\right)$ and the runaway temperature for sufficient time, the device should reached in an FTO type defect (Fig. 3b). This implies that in 
Table 2. Summary of short circuit tests performed on C2M0080120D 80m $\Omega$ / 1200V devices using a direct depolarization of $\mathrm{V}_{\mathrm{gs}}$

\begin{tabular}{ccccccccccc}
\hline $\mathbf{D U T}$ & $\mathbf{\# 1}$ & $\mathbf{\# 2}$ & $\mathbf{\# 3}$ & $\mathbf{\# 4}$ & $\mathbf{\# 5}$ & $\mathbf{\# 6}$ & $\mathbf{\# 7}$ & $\mathbf{\# 8}$ & $\mathbf{\# 9}$ & $\mathbf{\# 1 0}$ \\
\hline $\mathbf{V}_{\mathbf{d s}}(\mathbf{V})$ & 300 & 333 & 363 & 400 & 500 & 450 & 500 & 550 & 600 & 600 \\
\hline $\mathbf{V}_{\mathbf{g s}}(\mathbf{V})$ & 15 & 15 & 15 & 15 & 15 & 14 & 13 & 12 & 12 \\
\hline $\begin{array}{c}\text { Failure } \\
\mathbf{m o d e}\end{array}$ & FTO & FTO & FTO & FTO & FTS & FTO & FTO & FTO & FTS & FTS \\
\hline $\mathbf{T}_{\text {sc }}(\boldsymbol{\mu s})$ & 40 & 28 & 25 & 21 & 16 & 20 & 21 & 1.2 & 13 & 19 \\
\hline $\mathbf{E}_{\mathbf{s c}}(\mathbf{J})$ & 0.80 & 0.97 & 0.93 & 0.90 & 0.81 & 0.82 & 0.82 & 0.64 & 0.63 & 0.79 \\
\hline $\mathbf{P}\left(\mathbf{W} / \mathbf{m m}^{2}\right)$ & 1918 & 3316 & 3589 & 4102 & 4936 & 3948 & 3757 & 3418 & 4640 & 4014 \\
\hline
\end{tabular}

order to obtain the FTO failure, the temperature within the chip should not rise too quickly. According to equation (1) [15], there are two ways to decrease junction temperature in a shortcircuited chip: decrease $\mathrm{V}_{\mathrm{ds}}$ or decrease the density of saturation current by $\mathrm{V}_{\mathrm{gs}}$ depolarization.

$$
\Delta T_{\text {jmax }}(t)=\frac{2 \cdot V_{d s} \cdot J_{s a t}}{\rho c \sqrt{\pi \alpha}} \sqrt{t}
$$

where $\rho$ is the density of $\mathrm{SiC}, c$ is the specific heat of $\mathrm{SiC}, \alpha$ is the thermal diffusivity of $\mathrm{SiC}$ and $\mathrm{t}$ is the SC time.

In our study, to preserve a FTO under a $\mathrm{V}_{\mathrm{ds}}$ value close to the nominal voltage, an approach based on the direct depolarization of $\mathrm{V}_{\mathrm{gs}}$ is investigated. Short circuit tests are carried out by setting the gate source polarization value at $15 \mathrm{~V}$ and starting with a voltage $\mathrm{V}_{\mathrm{ds}}$ of $300 \mathrm{~V}$. Many commercial SiC MOSFET components have a FTO mode at a reduced $\mathrm{V}_{\mathrm{ds}}$. This voltage is the starting point of the study. If the test induces a secure failure mode FTO at this value of $\mathrm{V}_{\mathrm{gs}}$, then the $\mathrm{V}_{\mathrm{ds}}$ voltage is gradually increased by one step (between $33 \mathrm{~V}$ and $100 \mathrm{~V}$ ). On the other hand, if the test induces a FTS, then $\mathrm{V}_{\mathrm{gs}}$ is reduced with a step of 1V. Fig.3 summarizes the results of short circuit tests carried out on the C2M0080120D devices under various polarization conditions of $\mathrm{V}_{\mathrm{ds}}$ using a direct depolarization of $\mathrm{V}_{\mathrm{gs}}$. Table 2 presents for each DUT:

- $\quad$ the failure mode (FTO or FTS)

- the maximum short circuit duration $\mathrm{T}_{\mathrm{sc}}$,

- the maximum energy $E_{s c}=I_{d s m o y} . V_{d s} . T s c$,

- $\quad$ the dissipated power per unit area $P=I_{d s m o y} . V_{d s} /$ (surface of the chip).

It can be observed that direct polarization of $\mathrm{V}_{\mathrm{gs}}$ method shows a promising results in terms of $\mathrm{T}_{\mathrm{sc}}$ that exceeds $10 \mu \mathrm{s}$ (standard for IGBT device), and the appearance of FTO mode under a $\mathrm{V}_{\mathrm{ds}}$ close to the nominal value. From Fig. 3, three critical regions must be defined in order to choose an optimum short circuit bias conditions. The first region (1) appears for very low drain voltages where the device is in strong derating in $\mathrm{V}_{\mathrm{ds}}$. In this region, the device robustness is more assured by FTO mode, however its performance is penalized in terms of the converter efficiency and its cost. In the second zone (2), the device is placed under high $\mathrm{V}_{\mathrm{ds}}$ and $\mathrm{V}_{\mathrm{gs}}$ which reduce its robustness and leads to its degradation (appearance of a strong drain leakage and gate leakage currents) or to its failure with a FTO mode followed by a FTS or directly an FTS mode. For the third region (3), the device is placed under a small gate polarization (strong depolarization in $\mathrm{V}_{\mathrm{gs}}$ ), which generates an increase in $\mathrm{R}_{\mathrm{ds}(\mathrm{on})}$ and consequently losses in higher conduction. On the other hand, with a $\mathrm{V}_{\mathrm{gs}}$ too close to $\mathrm{V}_{\mathrm{gsth}}$ makes the device more sensitive to electron trapping effect at $\mathrm{SiC} / \mathrm{SiO}_{2}$ interface and $\mathrm{V}_{\mathrm{gsth}}$ drift [1617]. Also, due to the variability of local $\mathrm{V}_{\mathrm{gsth}}$ from one local MOSFET cell to another, a too low $\mathrm{V}_{\mathrm{gs}}$ can lead to a high current density inhomogeneity of the chip surface in the channel regions. Fig. 4 depicts the waveforms of the various voltages and currents obtained for the short circuit test performed on DUT\#8 under $\mathrm{V}_{\text {buffer }}=12 \mathrm{~V}$ and $\mathrm{V}_{\mathrm{ds}}=550 \mathrm{~V}$. From the Fig. 4, a delayed FTO with $5 \mu \mathrm{s}$ from the short circuit duration applied $\left(\mathrm{T}_{\mathrm{sc}}=18 \mu \mathrm{s}\right)$ is observed. Before the appearance of the FTO mode, a gate leakage current $\left(I_{\mathrm{gs}}\right)$ of $12 \mathrm{~mA}$ is measured, although the polarization is reduced to $12 \mathrm{~V}$, to around $2 / 3$ of the $\mathrm{T}_{\mathrm{sc}}$. During the short-circuit event, $I_{d s}$ slope variation can be noticed which results in the appearance of the drain leakage current very clear at turn-off. This drain leakage is always clearly visible from $500 \mathrm{~V}$.

Using the direct depolarization method of $\mathrm{V}_{\mathrm{gs}}$ is not always promising for keeping FTO a value of $\mathrm{V}_{\mathrm{ds}}$ closer to the nominal value. In Fig. 5, the short circuit characterization of DUT\#10 under $\mathrm{V}_{\text {buffer }}=11.2 \mathrm{~V}$ and $\mathrm{V}_{\mathrm{ds}}=600 \mathrm{~V}$, shows the appearance of the FTS failure mode which leads to catastrophic damage of the device. This failure mode appears after $4 \mu$ s from the applied short circuit duration $\left(\mathrm{T}_{\mathrm{sc}}=19 \mu \mathrm{s}\right)$. Fig. 5 illustrates the waveforms of the various resulting voltages and currents. The appearance of FTS failure mode is linked to the increase of the drain leakage current compared to the results obtained under the $\mathrm{V}_{\mathrm{ds}}=550 \mathrm{~V}$. On the other hand, the gate leakage current $\left(\mathrm{I}_{\mathrm{gsmax}}=10 \mathrm{~mA}\right)$ is less pronounced compared to the previous test $\left(\mathrm{I}_{\mathrm{gsmax}}=12 \mathrm{~mA}\right.$ at $\left.\mathrm{V}_{\text {buffer }}=12 \mathrm{~V}\right)$ due to the lower applied value of $\mathrm{V}_{\text {buffer. }}$.

\subsection{Gate source voltage estimation methodology}

To complete the direct depolarization method of $\mathrm{V}_{\mathrm{gs}}$, a second approach is developed to estimate the $V_{g s}$ value permitting to keep the appearance of FTO failure. This approach allows to investigate the critical dissipated power $\left(\mathrm{W} / \mathrm{mm}^{2}\right)$ boundary between FTO and FTS modes, responsible for the the 
device failure. The method is based on the results of two single pulse short circuit events. The first one leads to a FTO mode, and the second one induces a FTS mode.

The results of SC tests on DUT\#8 and DUT\#10 are analyzed for

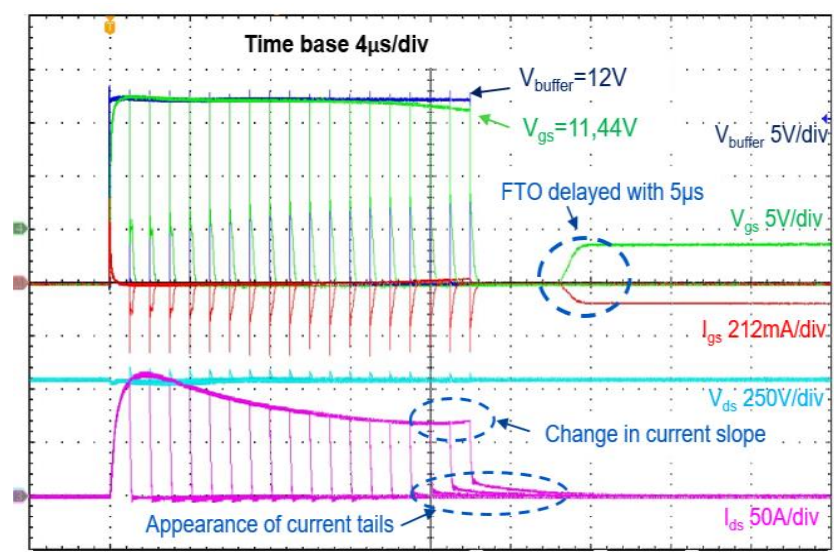

Fig. 4. Experimental waveforms during short circuit of the DUT\#8 $\left(\mathrm{V}_{\mathrm{ds}}=550 \mathrm{~V} ; \mathrm{V}_{\text {buffer(on/off) }}=+12 \mathrm{~V} /-5 \mathrm{~V} ; \mathrm{T}_{\text {case }}=25^{\circ} \mathrm{C} ; \mathrm{R}_{\mathrm{G}}=47 \Omega\right)$.

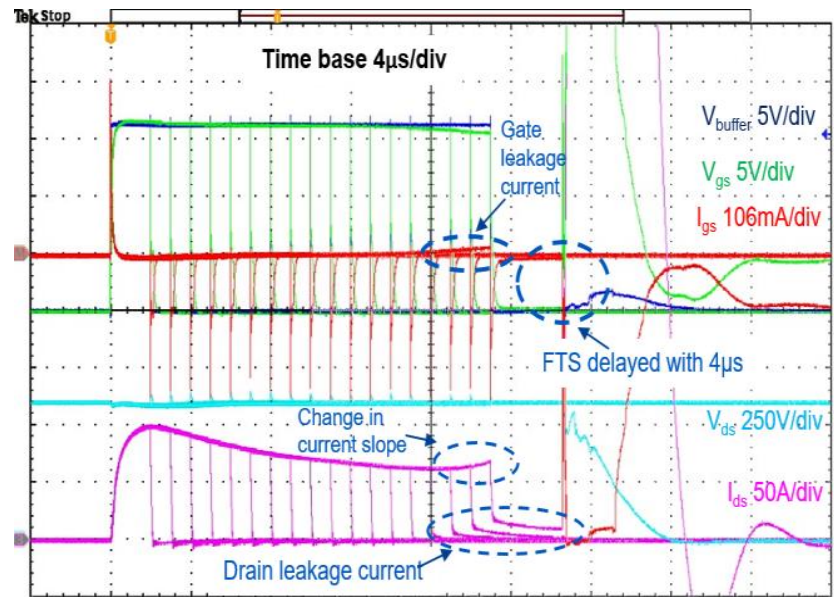

Fig. 5. Experimental waveforms during short circuit of the DUT\#10 ( $\mathrm{V}_{\mathrm{ds}}=600 \mathrm{~V}$; $\mathrm{V}_{\text {buffer(on/off })}=+11,2 \mathrm{~V} /-5 \mathrm{~V}$; Tcase $=25{ }^{\circ} \mathrm{C}$; $\left.\mathrm{R}_{\mathrm{G}}=47 \Omega\right)$.

such purpose. The first short circuit event performed on DUT\#8, under $\mathrm{V}_{\mathrm{ds}}=550 \mathrm{~V}$ and $\mathrm{V}_{\mathrm{gs}}=12 \mathrm{~V}$, shows a dissipated power of $\mathrm{P}_{\mathrm{FTO}}=3418 \mathrm{~W} / \mathrm{mm}^{2}$ leading to appearance of FTO failure. While the second event carried out on DUT\#10, under $V_{\mathrm{ds}}=600 \mathrm{~V}$ and $\mathrm{V}_{\mathrm{gs}}=11.2 \mathrm{~V}$, presents a dissipated power of $\mathrm{P}_{\mathrm{FTS}}=4014 \mathrm{~W} / \mathrm{mm}^{2}$ leading to appearance of FTS failure. The dissipated power is expressed by equation (2).

$$
P=V_{d s} \cdot I_{d s m o y}
$$

In small signal of $V_{\mathrm{gs}}$ variation, the $\mathrm{I}_{\mathrm{dsmoy}}$ current can be presented by equation (3).

$$
I_{d s m o y}=K_{L V} \cdot\left(V_{g s}-V_{g s t h}\right)^{2}
$$

where $\mathrm{K}_{\mathrm{LV}}\left(\mathrm{A} / \mathrm{V}^{2}\right)$ is a constant that represents transconductance parameter in Low Voltage $(\mathrm{LV})$ of $\mathrm{V}_{\mathrm{gs}}$.

For $\mathrm{V}_{\mathrm{gs}}$ values higher than the threshold voltage $\mathrm{V}_{\mathrm{gsth}}\left(\mathrm{V}_{\mathrm{gs}}>>\right.$ $\mathrm{V}_{\mathrm{gsth}}$ ), the operating device can be placed in the large signal of saturation zone (i.e proportionality relation). Therefore, equation (3) can be expressed by equation (4).

Table 3. Short circuit test results using a $V_{\text {gs }}$ estimation method

\begin{tabular}{lll} 
DUT & $\# 11$ & $\# 12$ \\
\hline $\mathbf{V}_{\mathbf{d s}}(\mathbf{V})$ & 600 & 600 \\
\hline $\mathbf{V}_{\mathbf{g s}}(\mathbf{V})$ & 10 & 10 \\
\hline Tsc $(\boldsymbol{\mu s})$ & 24 & 23 \\
\hline $\mathbf{P}_{\mathbf{m e s}}\left(\mathbf{W} / \mathbf{m m}^{\mathbf{2}}\right)$ & 3440 & 3549 \\
\hline $\mathbf{P}_{\text {est }}\left(\mathbf{W} / \mathbf{m m}^{\mathbf{2}}\right)$ & 3418 & 3418 \\
\hline
\end{tabular}

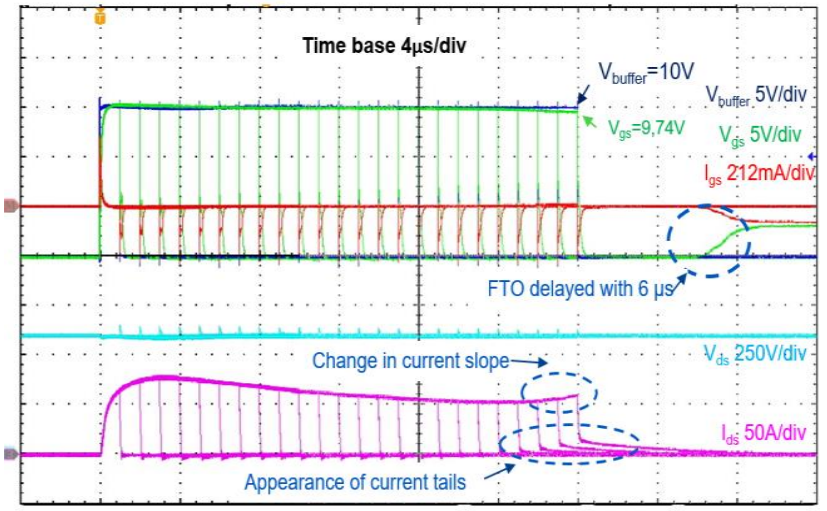

Fig. 6. Experimental waveforms during short circuit of the DUT\#11 $\left(\mathrm{V}_{\mathrm{ds}}=600 \mathrm{~V} ; \mathrm{V}_{\text {buffer }(\mathrm{on} / \text { off }}=+10 \mathrm{~V} /-5 \mathrm{~V} ; \mathrm{T}_{\text {case }}=25^{\circ} \mathrm{C} ; \mathrm{R}_{\mathrm{G}}=47 \Omega\right)$.

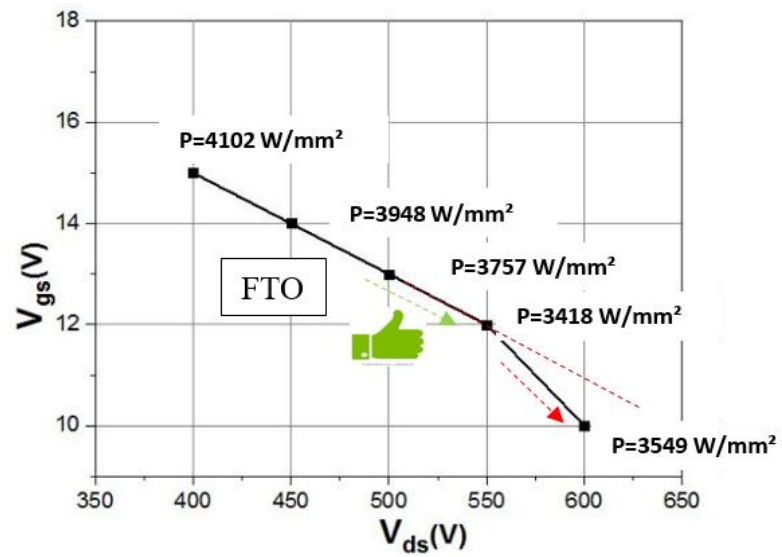

Fig. 7. Evolution of $\mathrm{V}_{\mathrm{gs}}$ as a function of $\mathrm{V}_{\mathrm{ds}}$ according to iso-power (P) criterion and FTO failure mode.

$$
I_{d s m o y}=K_{H V} \cdot\left(V_{g s}-V_{g s t h}\right)
$$

where $\mathrm{K}_{\mathrm{HV}}$ is a constant that represents transconductance parameter in High Voltage (HV) of $\mathrm{V}_{\mathrm{gg}}$.

Consequently, the dissipated power $\mathrm{P}$ is related to $\mathrm{V}_{\mathrm{gs}}$ voltage through equation (5). 


$$
P=V_{d s} \cdot K_{H V} \cdot\left(V_{g s}-V_{g s t h}\right)
$$

For DUT\#8 that presents a FTO mode under $\mathrm{V}_{\mathrm{ds}}=550 \mathrm{~V}$, $\mathrm{V}_{\mathrm{gs}}=12 \mathrm{~V}, \mathrm{~V}_{\mathrm{gsth}}=2.61 \mathrm{~V}$ and $\mathrm{P}_{\mathrm{FTO}}=3418 \mathrm{w} / \mathrm{mm}^{2}$, the transconductance $\mathrm{K}_{\mathrm{HV}}$ is calculated as:

$$
K_{H V}=K_{F T O}=\frac{P_{F T O}}{V_{d s} \cdot\left(V_{g s}-V_{g s t h}\right)}=0.661 \mathrm{~A} / \mathrm{V} \cdot \mathrm{mm}^{2}
$$

From this result, we found that the $\mathrm{V}_{\mathrm{gs}}$ estimated $\left(\mathrm{V}_{\mathrm{gs} \_\mathrm{es}}\right)$

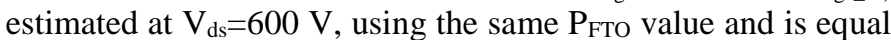
to $11.22 \mathrm{~V}$. However, it has been demonstrated that this value of $\mathrm{V}_{\mathrm{gs} \_ \text {es }}$ induces a FTS mode on DUT\#10. The $K_{H V}$ is a posteriori calculated for $\left(\mathrm{P}_{\mathrm{FTS}}=4014 \mathrm{w} / \mathrm{mm}^{2}\right)$ and $\mathrm{V}_{\mathrm{ds}}=600 \mathrm{~V}$.

$$
K_{H V}=K_{F T S}=\frac{4014}{600 .(11.22-2.61)}=0.779 \mathrm{~A} / \mathrm{V} \cdot \mathrm{mm}^{2}
$$

Then, $\mathrm{V}_{\mathrm{gs} \_ \text {es }}$ is estimated more precisely for a test under $\mathrm{V}_{\mathrm{ds}}=600 \mathrm{~V}$ with a dissipated power leading to a FTO $\left(\mathrm{P}_{\mathrm{FTO}}\right)$ and the calculated $\mathrm{K}_{\mathrm{FTS}}$ coefficient:

$$
V_{g S_{-} e s}=\frac{P_{F T O}}{V_{d s \times K_{F T S}}}+V_{g s t h} \cong 10 \mathrm{~V}
$$

This method allows to find the $\mathrm{V}_{\mathrm{gs}}$ interval which ensures a FTO mode at $\mathrm{V}_{\mathrm{ds}}=600 \mathrm{~V}$ :

$$
10 \mathrm{~V} \leq \mathrm{V}_{\mathrm{gs} \_ \text {es }}<11.22 \mathrm{~V}
$$

To validate this method of $\mathrm{V}_{\mathrm{gs}}$ estimation from the dissipated power density, the short-circuit test is performed under the voltage $\mathrm{V}_{\text {buffer }}=10 \mathrm{~V}$ and $\mathrm{V}_{\mathrm{ds}}=600 \mathrm{~V}$ on two DUTs in order to evaluate the repetitiveness of the proposed approach. Table 3 presents the short circuit test duration $\left(\mathrm{T}_{\mathrm{sc}}\right)$, the measured dissipated power $\left(\mathrm{P}_{\mathrm{mes}}\right)$ compared to the estimated dissipated power $\left(\mathrm{P}_{\text {est }}\right)$ that confirm the validity of the new approach for the two DUTs. Fig. 6 illustrates the waveforms results of short circuit test performed on DUT\#11. It can be observed that the secure failure mode FTO appears after $6 \mu$ s from the applied short-circuit duration $\left(\mathrm{T}_{\mathrm{sc}}=24 \mu \mathrm{s}\right)$. The gate leakage current $\left(I_{\mathrm{gsmax}}=2.5 \mathrm{~mA}\right)$ is less pronounced compared to the previous test $\left(I_{\text {gsmax }}=12 \mathrm{~mA}\right.$ at $V_{\text {buffer }}=12 \mathrm{~V}$ and $I_{\text {gsmax }}=10 \mathrm{~mA}$ at $\mathrm{V}_{\text {buffer }}=11.2 \mathrm{~V}$ ) given the low value of the applied voltage $\left(\mathrm{V}_{\text {buffer }}=10 \mathrm{~V}\right)$. The drain leakage is high because $\mathrm{V}_{\mathrm{ds}}$ has a high value of $600 \mathrm{~V}$. However, this leakage current remains the same magnitude as for the test for $550 \mathrm{~V}$ preserving the FTO failure. This observation proves that the applied power density over the duration $\mathrm{T}_{\mathrm{sc}}$ is preserved to give the same failure mode.

By associating the two approach results presented previously, it can be identified that the damaged devices in FTO mode follows a quasi linear $\mathrm{V}_{\mathrm{gs}}-\mathrm{V}_{\mathrm{ds}}$ characteristics (Fig. 7) which becomes improvable at high voltage close to $600 \mathrm{~V}$ due to the appearance of a drain leakage causing a delayed FTO/FTS sequence. This trend allows the prediction of $\mathrm{V}_{\mathrm{gs}}$ that leads to the appearance of a FTO.

\section{Penalty of the $V_{g s}$ depolarization on the $R_{d s(o n)}$ resistance}

The impact of $\mathrm{V}_{\mathrm{gs}}$ depolarization approaches on $\mathrm{R}_{\mathrm{ds}(\mathrm{on})}$ resistance must be investigated. Fig. 8 presents the $R_{d s(o n)}$ resistance evolution as a function of the $V_{g s}$ voltage at two

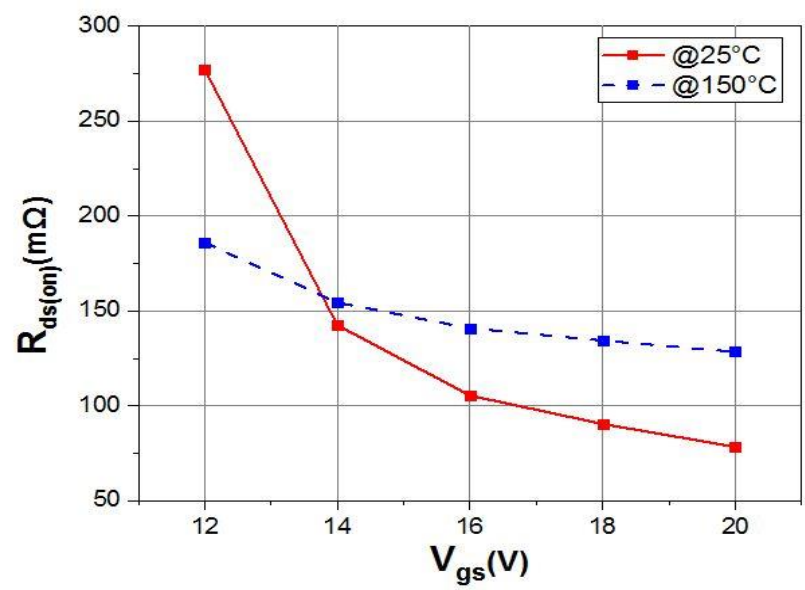

Fig. 8. $\mathrm{R}_{\mathrm{ds}(\mathrm{on})}$ as a function of $\mathrm{V}_{\mathrm{gs}}$ at two temperatures $25^{\circ} \mathrm{C}$ and $150^{\circ} \mathrm{C}$ for $\mathrm{C} 2 \mathrm{M} 0080120 \mathrm{D}$ device.

temperatures $25{ }^{\circ} \mathrm{C}$ and $150{ }^{\circ} \mathrm{C}$. These results were obtained from the datasheet. It can be observed that relative variation of $\mathrm{R}_{\mathrm{ds}(\mathrm{on})}$ against $\mathrm{V}_{\mathrm{gs}}$ voltage is $+247 \%$ at $25{ }^{\circ} \mathrm{C}$ and only $+44 \%$ at $150{ }^{\circ} \mathrm{C}$. Moreover, if we consider that the conduction losses only account $50 \%$ of the total losses, thus the $\mathrm{V}_{\mathrm{gs}}$ depolarization will represent an acceptable impact on $\mathrm{R}_{\mathrm{ds}(\text { on })} @ 150{ }^{\circ} \mathrm{C}$ with a $22 \%$ ratio. The reduction of the $\mathrm{R}_{\mathrm{ds}(\mathrm{on})}$ penalty at $\mathrm{Tj}=150{ }^{\circ} \mathrm{C}$ is physically related to the mobility behavior affected by Coulomb scattering [18]. Indeed, the mobility in the channel is governed at low polarization by Coulomb scattering mechanism which becomes dominant compared to the others mechanisms in particular surface acoustic scattering for the JFET and drift regions. The Coulomb mobility has a positive thermal sensitivity coefficient for a $\mathrm{T}_{\text {case }}$ range between $25{ }^{\circ} \mathrm{C}$ and $200{ }^{\circ} \mathrm{C}$. Therefore, the channel resistance decreases when the case temperature of the chip in operation increases.

However, the other resistances of JFET and drifts regions increase with the temperature rise. Consequently, a compensation effect appears and becomes more effective as $\mathrm{V}_{\mathrm{gs}}$ is reduced. At a given $\mathrm{V}_{\mathrm{gs}}$, there is an optimum case temperature which gives the lowest total value of $\mathrm{R}_{\mathrm{ds}(\mathrm{on})}$ corresponding to a state of thermal effects compensation between the resistive terms.

\section{Conclusion}

In this paper, planar gate structure SiC MOSFETs robustness has been experimentally evaluated under short circuit operation. The obtained results confirm the existence of two failure modes (FTO and FTS) for thirteen devices $\left(80 \mathrm{~m} \Omega / 1.2 \mathrm{kV}, 2^{\text {nd }} \mathrm{Gen}\right)$. 
Two approaches based on direct depolarization of $\mathrm{V}_{\mathrm{gs}}$ are developed to ensure a secure failure mode FTO at $\mathrm{V}_{\mathrm{ds}}$ close to the nominal value i.e $\mathrm{V}_{\mathrm{BRmin}} / 2$. The direct depolarization approach shows promising results in terms of short circuit duration $\left(\mathrm{T}_{\mathrm{sc}}\right)$ that exceeds $10 \mu \mathrm{s}$, and the appearance of FTO mode taking into account a maximum power density around $3.5 \mathrm{~kW} . \mathrm{mm}^{-2}$. This critical value is identified as the power density boundary between FTO and FTS modes. For these devices, the $\mathrm{V}_{\mathrm{gs}}$ estimated from the dissipated power calculations leads to a FTO appearance at $V_{d s}=600 \mathrm{~V}$. The study of $\mathrm{R}_{\mathrm{ds}(\mathrm{on})}$ resistance evolution as a function of $\mathrm{V}_{\mathrm{gs}}$, shows that $\mathrm{V}_{\mathrm{gs}}$ depolarization impacts $\mathrm{R}_{\mathrm{ds}(\mathrm{on})}$ in acceptable way at $150{ }^{\circ} \mathrm{C}$. This approaches have been validated on other current rating devices $(25 \mathrm{~m} \Omega / 1.2 \mathrm{kV})$ and for voltage rating devices $(45 \mathrm{~m} \Omega / 1.7 \mathrm{kV})$ from the same manufacturer. However, the trench gate-structure evaluated did not show satisfying results for $\mathrm{V}_{\mathrm{gs}}$ depolarization approach. The results may provide useful indicators for converter design and fault protection conditions of $\mathrm{SiC}$ power MOSFETs with planar structure.

\section{References}

[1] K. Shenai, "The figure of merit of a semiconductor power electronics switch", IEEE Transactions on Electron Devices, vol. 65, no. 10, pp. 4216-4224, Oct 2018.

[2] X. She, A.Q. Huang, Ó. Lucía, B. Ozpineci, "Review of silicon carbide power devices and their application", IEEE Trans. Ind. Electron. 64 (10) (Oct. 2017) 8193-8205.

[3] T. Wu, J. Chen, S. Mao, M.J. Schutten, "1200 V SiC MOSFETS for high voltage power conversion", Proc. IEEE Energy Conversion Congress and Exposition (ECCE), Raleigh, NC, 2012, pp. 29212926.

[4] D. Othman, S. Lefebvre, M. Berkani, Z. Khatir, A. Ibrahim, A. Bouzourene, "Robustness of $1.2 \mathrm{kV} \mathrm{SiC} \mathrm{MOSFET} \mathrm{devices",}$ Microelectronics Reliability, vol. 53, no. 9-11, pp. pp 1735-1738, Sept.-Nov. 2013.

[5] M. Riccio, a. Castellazzi, G. De Falco, A. Irace, "Experimental analysis of electro-thermal instability in SiC Power MOSFETs", Microelectron. Reliab. 53 (9-11) (2013) pp.1739-1744.

[6] A. Castellazzi, A. Fayyaz, L. Yang, M. Riccio and A. Irace, "Shortcircuit robustness of $\mathrm{SiC}$ Power MOSFETs: Experimental analysis", 2014 IEEE 26th International Symposium on Power Semiconductor Devices \& IC's (ISPSD), Waikoloa, HI, 2014, pp.
71-74.

[7] Z. Wang, et al., "Temperature-dependent short-circuit capability of silicon carbide power MOSFETs", IEEE Trans. Power Electron. 31 (2) (Feb. 2016) 1555-1566.

[8] C. Chen, D. Labrousse, S. Lefebvre, M. Petit, C. Buttay, H. Morel, "Study of short-circuit robustness of SiC MOSFETs, analysis of the failure modes and comparison with BJTs", Microelectronics Reliability. 55 (9-10) (Aug.2015) pp. 1708-1713.

[9] D. Pappis, P. Zacharias, "Failure modes of planar and trench $\mathrm{SiC}$ MOSFETs under single and multiple short circuits conditions", 19th European Conference on Power Electronics and Applications (EPE'17 ECCE Europe), Warsaw, 2017 pp. P.1-P.11.

[10] J. Liu, G. Zhang, B. Wang, W. Li and J. Wang, "Gate Failure Physics of SiC MOSFETs Under Short-Circuit Stress", in IEEE Electron Device Letters, vol. 41, no. 1, pp. 103-106, Jan. 2020.

[11] F. Boige, F. Richardeau, S. Lefebvre, J.-M. Blaquière, G. Guibaud, A. Bourennane, "Ensure an original and safe "fail-to-open" mode in planar and trench power SiC MOSFET devices in extreme shortcircuit operation", Microelectronic. Reliability., vol. 88-90, pp. 598-603, Sep. 2018.

[12] F. Boige, F. Richardeau, D. Trémouilles, S. Lefebvre, G. Guibaud. "Investigation on damaged planar-oxide of $1200 \mathrm{~V} \mathrm{SiC}$ power MOSFETs in non-destructive short-circuit operation", Microelectronics Reliability, Elsevier, 2017, 76-77, pp.500 - 506.

[13] Cree, C2M0080120D-SiC MOSFET Datasheet, (2015).

[14] G. Romano, A. Fayyaz, M. Riccio, L. Maresca, G. Breglio, A. Castellazzi, and A. Irace, "A Comprehensive Study of Short-Circuit Ruggedness of Silicon Carbide Power MOSFETs”, IEEE J. Emerg. Sel. Top. Power Electron., vol. 4, no. 3, pp. 978-987, Sep. 2016.

[15] S. Clemente, "Transient thermal response of power semiconductors to short power pulses" in IEEE Transactions on Power Electronics, vol. 8, no. 4, pp. 337-341, Oct. 1993.

[16] P.D. Reigosa, F. Iannuzzo, L. Ceccarelli, "Effect of short-circuit stress on the degradation of the $\mathrm{SiO} 2$ dielectric in $\mathrm{SiC}$ power MOSFETs", Microelectronic Reliability 88-90 (2018) 577-583

[17] A. J. Lelis, D. Habersat, R. Green, A. Ogunniyi, M. Gurfinkel, J. Suehle, N. Goldsman, "Time Dependence of Bias-Stress-Induced SiC MOSFET Threshold-Voltage Instability Measurements" in IEEE Transactions on Electron Devices, vol. 55, no. 8, pp. 18351840, Aug. 2008.

[18] S L Rumyantsev, M S Shur, M E Levinshtein, P A Ivanov, J W Palmour, A K Agarwal, B A Hull and Sei-Hyung Ryu, "Channel mobility and on-resistance of vertical double implanted $4 \mathrm{H}-\mathrm{SiC}$ MOSFETs at elevated temperatures", Semiconductor Science and Technology. vol24.no 4.075011, 2009. 